\title{
Permainan Kartu Gambar Dengan Metode Cantol Roudhoh Di Kelompok B TK Mahkota Selong
}

\author{
Muslihatun Maulidian', Suhirman², Zuhut Ramdani', \\ PAUD Mahkota Selong; Universitas Hamzanwadi; Universitas Hamzanwadi \\ Email: maulidsaputri456@gmail.com; suhirman.sakti@gmail.com;
}

\begin{abstract}
Abstrak
Penelitian ini didasari oleh rendahnya kemampuan anak didik dalam mengenal kata dalam pembelajaran. Penelitian ini bertujuan untuk meningkatkan kemampuan pengenalan kata melalui permainan kartu gambar menggunakan metode cantol roudhoh di kelompok B TK Mahkota Selong tahun ajaran 2017/2018. Jenis penelitian ini merupakan Penelitian Tindakan Kelas yaitu guru yang berperan langsung dalam proses pembelajaran. Subjek penelitian ini adalah anak kelompok B TK Mahkota Selong Tahun pembelajaran 2017/2018 dengan jumlah anak sebanyak 25 anak Berdasarkan hasil penelitian diketahui bahwa rata-rata persentase terhadap kemampuan pengenalan kata pada anak kelas B TK Mahkota Selong pada sebelum tindakan mencapai 33\% untuk jawaban alternatif "Ya" dengan kategori "Rendah". Setelah dilakukan tindakan pada siklus I dengan penerapan metode Cantol Roudhoh, kemampuan mengenal kata pada anak meningkat menjadi 56\% untuk jawaban alternatif "Ya" dengan kategori "Sedang". perbaikan pada siklus II kemampuan mengenal kata pada anak meningkat menjadi $78 \%$ untuk jawaban alternatif "Ya" dengan kategori "Baik" yang artinya ada peningkatan. Dan dilakukan perbaikan pada siklus III kemampuan mengenal kata pada anak kembali meningkat menjadi 95\% untuk jawaban alternatif "Ya" dengan kategori "Baik Sekali
\end{abstract}

Kata Kunci: Kartu Bergambar;Metode Cantol Roudhoh; Pengenalan Kata, PTK,

\section{Abstract}

This research was based on the students tack to recognize the word in learning. This study aims to improve the ability of word recognition through drawing card games using the cantol roudhoh method in group B TK Mahkota Selong in the 2017/2018 academic year. This type of research was Classroom Action Research which is a teacher who plays a direct role in the learning process. The subjects of this study were students of group B TK Mahkota Selong in the academic Year 2017/2018 consisting 25 student. While the object of this research was the application of cantol roudhoh method in improving the ability of word recognition through flashcard games in group B TK Mahkota Selong. Based on the results of the study, the average percentage of the ability of word recognition in group B TK Mahkota Selong before treatment was 33\% for the alternative answer "Yes" with the category "Low". After taking action in cycle I with the application of the Cantol Roudhoh method, the ability to recognize words in students increased to $56 \%$ for the alternative answer "Yes" with the category "Medium". As for the improvement in cycle II the ability to recognize words in students increased to $78 \%$ for alternative answers "Yes" with the category "Good" which means there was increased. In cycle III 95\% for alternative answers "Yes" with the category "Very Good".

Keywords : Flashcard.; Cantol Roudhoh Method, Word Recognition, Action Research, 


\section{PENDAHULUAN}

Anggapan bahwa pendidikan baru bisa dimulai setelah usia Sekolah Dasar (SD) yaitu usia tujuh tahun ternyata tidaklah benar. Hasil penelitian dibidang Neurologi yang dilakukan Benyamin S. Bloom, seorang ahli pendidikan dari Universitas Chikago, Amerika Serikat, mengemukakan bahwa pertumbuhan sel jaringan otak anak pada usia 0-4 tahun mencapai 50\%, hingga usia 8 tahun mencapai 80\% (Musbikin,Imam. 2010:71). Artinya bila pada usia tersebut otak anak tidak mendapatkan rangsangan secara maksimal maka otak anak tidak akan berkembang secara optimal. Oleh karena itu layanan pendidikan kepada anak-anak usia dini merupakan dasar yang sangat berpengaruh terhadap perkembangan anak selanjutnya hingga dewasa.

Berbagai teori belajar pada anak seperti teori Peaget, Vygotsky, Montesori, Bandura, Case, Bruner, dan Smilansky menjelaskan cara belajar anak dari berbagai sudut pandang yang berbeda (Musbikin,Imam. 2010:70). Oleh karena itu, teori belajar tersebut perlu dipilih dan disesuaikan dengan karakteristik anak dan materi ajarnya. Materi yang diberikan juga bervariasi, termasuk menjadikan anak siap belajar membaca, berhitung dan menulis. Memberikan pembelajaran kepada anak termasuk pembelajaran membaca permulaan harus disesuaikan dengan kemampuan anak, minat anak dan faktor-faktor yang mempengaruhi proses membaca permulaan untuk anak usia dini yang bisa dikenalkan melalui kemampuan mengenal kata dengan metode yang menarik dan menyenangkan. Kemampuan mengenal kata merupakan kemampuan dasar pada membaca permulaan dan akan berpengaruh terhadap kemampuan membaca lanjut.

Banyak lembaga pendidikan SD yang sering dianggap sebagai lembaga pendidikan berkualitas dan bonafit, seringkali mengajukan persyaratan tes membaca dan menulis bagi peserta didik yang masuk mendaftar kesekolah tersebut. Selain itu kebanyakan guru di SD terutama kelas 1 menekankan kepada muridnya harus bisa membaca dan menulis. Hal ini mendorong lembaga pendidikan TK atau sederajad, berlomba-lomba mengajarkan kemampuan akademik membaca dan menulis dengan mengadopsi pola-pola pembelajaran di SD. Akibatnya tidak jarang TK yang tidak lagi menerapkan prinsip-prinsip bermain sambil belajar atau belajar seraya bermain. Sehingga TK tidak lagi taman paling indah dan berteman banyak, tetapi beralih menjadi sekolah TK dalam menyekolahkan anak-anaksecara dini. Salah satu tandanya adalah dengan adanya penargetan kemampuan membaca dan menulis agar bisa melanjutkan ke SD yang favorit.

Hal tersebut sudah menggeser pandangan bahwa TK merupakan lembaga pendidikan pra sekolah, yang tidak mengemban tanggung jawab utama dalam membina kemampuan akademik anak seperti kemampuan membaca dan menulis. Substansi pembinaan kemampuan akademik ini harus menjadi tanggung jawab utama pendidikan SD. Karena sebetulnya tugas utama lembaga pendidikan PAUD sebagai lembaga pendidikan pra sekolah adalah mempersiapkan anak dengan memperkenalkan berbagai 
macam pengetahuan, sikap prilaku, keterampilan dan intelektual agar dapat beradaptasi dengan kegiatan belajar sesungguhnya di SD. Akan tetapi hal tersebut sudah lazim terjadi dimana-mana, maka apabila lembaga pendidikan TK tidak mengajarkan membaca dan menulis akan dikatakan sebagai lembaga pendidikan TK yang tidak bermutu dan tidak diminati oleh masyarakat.

Di TK Mahkota Lingkungan Kebontalo Kelurahan Selong dalam melaksanakan pembelajaran membaca melalui pengenalan kata menggunakan metode konvensional dengan mengeja huruf yang ditulis di papan tulis, dimana pembelajaran berpusat pada guru. Media yang digunakan masih terbatas hanya menggunakan majalah dan papan tulis. Anak akan diminta untuk mengerjakan tugas yang ada didalam majalah dan meminta mereka untuk menuliskannya kembali ke dalam buku tugas mereka, setelah itu anak akan mengeja huruf yang telah ditulis sesuai dengan perintah guru. Hal ini mengakibatkan anak menjadi kurang tertarik dalam mengikuti pembelajaran, banyak anak yang tidak bersemangat dan masih sulit mengikutinya. Idealnya anak kelompok B yang rata-rata berusia 5-6 tahun yang sudah siap memasuki Sekolah Dasar (SD), sudah mampu mengenal kata yang terdiri dari 5-6 kata, sudah mampu mengucapkan kata mencapai 2000-2500 kata, sudah bisa memahami pesan baru yang diterimanya, mampu bercakapcakap dengan bahasa yang komplek dan sudah dapat melakukan percakapan tanpa memonopoli pembicaraan (Iroh, Siti Zahroh, dkk.19:2010). Tapi kenyataannya masih banyak anak kelompok B yang belum bisa mengenal kata dengan baik, belum memahami pesan sederhana yang disampaikan oleh guru, belum memiliki kosakata yang banyak sehingga mengakibatkan anak masih belum bisa membaca sederhana, masih malu-malu dalam bercakap-cakap dengan guru maupun teman sebayanya menggunakan bahasa yang komplek.

Berdasarkan pertimbangan tersebut maka peneliti ingin mengembangkan kemampuan mengenal kata sebagai modal awal untuk anak bisa membaca pada anak usia dini khususnya di kelompok B TK Mahkota Selong, dalam hal membaca huruf vokal dan konsonan, membaca huruf yang dirangkai dengan suku kata, membaca suku kata yang dirangkai menjadi kata, dan membaca kata yang dirangkai menjadi kalimat sederhana menggunakan metode Cantol Roudhoh. Dalam penerapannya metode ini menggunakan media ved cantol roudhoh yang berisi lagu 21 cantolan suku kata ba, bi, bu, be, bo sampai dengan za, zi, zu, ze, zo. Ved cantol roudhoh yang berisi petualangan Zahra di Pulau membaca dan permainan jam warna dengan membaca suku kata.

\section{METODE PENELITIAN}

Penelitian ini menggunakan jenis penelitian tindakan kelas (PTK) yaitu suatu bentuk kajian yang bersifat reflektif oleh pelaku tindakan (Adimas, Prasetyo. 31:2012). Tindakan tersebut dilakukan untuk meningkatkan kemantapan rasional dari tindakantindakan mereka dalam melaksanakan tugas sehari-hari, memperdalam pemahaman terhadap tindakan-tindakan yang dilakukan, serta memperbaiki kondisi dimana praktik- 
praktik pembelajaran tersebut dilakukan. Untuk mewujudkan tujuan-tujuan tersebut, PTK dilaksanakan dalam proses berbaur (cyclical), yang terdiri atas empat tahapan yaitu planing, action, observation, evaluation dan reflection (Asmani,Jamal Makmur. 2015:105).

Penelitian tindakan kelas ini dilaksanakan di TK Mahkota Selong. Waktu penelitian dilakukan selama dua bulan yaitu pada bulan April- Mei 2018. Adapun subjek penelitian ini adalah semua anak yang ada dikelompok B TK MAHKOTA Selong tahun ajaran 2017/2018, dengan jumlah anak sebanyak 25 anak. Penelitian ini direncanakan terdiri dari 3 siklus. Hal ini dimaksudkan agar peserta didik dapat beradaptasi dengan metode cantol yang diteliti. Model siklus tindakan yang digunakan adalah model Kurt Lewin. Kurt Lewin menjelaskan ada 4 hal yang harus dilakukan dalam proses PTK yakni perencanaan, tindakan, observasi, dan refleksi (Sanjaya,Wina. 2009:49). Dalam penelitian ini tehnik pengumpulan data dilakukan dengan cara sebagai berikut:

Dalam penelitian ini, peneliti menggunakan instrumen untuk mengumpulkan data berupa: catatan lapangan (FieldNote), Lembar observasi, dan dokumentasi. Dalam penelitian ini analisis dilakukan peneliti sejak awal pada setiap aspek penelitian. Analisis data dari penelitian ini menggunakan tehnik analisis statistik deskriptif yaitu fase statistika yang hanya menggambarkan dan menganalisis kelompok data yang diberikan tanpa penarikan kesimpulan mengenai kelompok data yang lebih besar. Data yang dianalisis secara deskriptip ini menggunakan tehnik presentase yang bertujuan untuk melihat kecendrungan yang terjadi dalam kegiatan pembelajaran. Dengan rumus :

$\mathrm{P}=\underset{\bar{N}}{\mathrm{Fx}} 100 \%$

Keterangan :

$\mathrm{P}=$ Persentase

$\mathrm{F}=$ Frekuensi

$\mathrm{N}=$ Jumlah Objek

Dengan menggunakan acuan tingkat ketuntasan hasil belajar yang yakni batas ketuntasan secara klasikal dari hasil belajar anak adalah 75-85\% (Johni Dimyati, 2013:105). Dengan rincian sebagai berikut :

$<40 \% \quad=$ Sangat Tidak Baik

$40 \%-55 \%=$ Tidak baik

$56 \%-75 \%=$ Cukup

$76 \%-85 \%=$ Baik

$86 \%-100 \%=$ Sangat Baik

\section{HASIL PENELITIAN DAN PEMBAHASAN}

Hasil 
Berdasarkan hasil penelitian yang di lakukan pada siklus I, siklus II dan Siklus III ternyata kemampuan pengenalan kata melalui permainan kartu gambar dengan metode Cantol Roudhoh di kelompok B TK Mahkota Selong tahun ajaran 2017/2018 mengalami peningkatan yang signifikan jika dibandingkan ketika sebelum diberikan tindakan. Berdasarkan hasil penelitian diketahui bahwa rata-rata persentase terhadap kemampuan pengenalan kata pada anak kelas B TK Mahkota Selong pada sebelum tindakan mencapai 33\% untuk jawaban alternatif "Ya" dengan kategori "Rendah".

Setelah dilakukan tindakan pada siklus I dengan penerapan metode Cantol Roudhoh, kemampuan mengenal kata pada anak meningkat menjadi 56\% untuk jawaban alternatif "Ya" dengan kategori "Sedang". Adapun setelah dilakukan perbaikan pada siklus II kemampuan mengenal kata pada anak meningkat menjadi 78\% untuk jawaban alternatif "Ya" dengan kategori "Baik" yang artinya ada peningkatan. Dan dilakukan perbaikan pada siklus III kemampuan mengenal kata pada anak kembali meningkat menjadi 95\% untuk jawaban alternatif "Ya" dengan kategori "Baik Sekali". Artinya ada peningkatan yang signifikan terhadap kemampuan mengenal kata pada anak kelompok B TK Mahkota Selong.

Untuk lebih jelas melihat perbandingan persentase peningkatan kemampuan pengenalan kata melalui permainan kartu gambar dengan metode Cantol Roudhoh di kelompok B TK Mahkota Selongtahun ajaran 2017/2018 dari pra tindakan, siklus I, siklus II dan siklus III dapat dilihat pada tabel berikut ini :

Tabel.

Rekapitulasi Pra Tindakan, Siklus I, II, Dan III

\begin{tabular}{|c|c|c|c|c|c|c|c|c|c|}
\hline \multirow{4}{*}{$\begin{array}{l}\mathrm{N} \\
\mathrm{O}\end{array}$} & \multirow{4}{*}{$\begin{array}{l}\text { ASPEK YANG DI } \\
\text { OBSERVASI }\end{array}$} & \multicolumn{8}{|c|}{ PERSENTASE ( P ) } \\
\hline & & \multirow{2}{*}{\multicolumn{2}{|c|}{$\begin{array}{l}\text { SEBELUM } \\
\text { TINDAKAN }\end{array}$}} & \multirow{2}{*}{\multicolumn{2}{|c|}{ SIKLUS I }} & \multirow{2}{*}{\multicolumn{2}{|c|}{ SIKLUS II }} & \multirow{2}{*}{\multicolumn{2}{|c|}{$\begin{array}{c}\text { SIKLUS } \\
\text { III }\end{array}$}} \\
\hline & & & & & & & & & \\
\hline & & $\mathrm{Ya}$ & $\mathrm{Tdk}$ & $\mathrm{Ya}$ & $\mathrm{Tdk}$ & $\mathrm{Ya}$ & Tdk & $\mathrm{Ya}$ & $\mathrm{Tdk}$ \\
\hline 1 & $\begin{array}{l}\text { Anak dapat mengenal } \\
\text { huruf abjad dengan baik. }\end{array}$ & $\begin{array}{l}68 \\
\%\end{array}$ & $32 \%$ & $100 \%$ & - & $100 \%$ & - & $\begin{array}{c}100 \\
\%\end{array}$ & - \\
\hline 2 & $\begin{array}{l}\text { Anak mampu mengenal } \\
\text { suku kata dengan baik. }\end{array}$ & $\begin{array}{l}36 \\
\%\end{array}$ & $64 \%$ & $80 \%$ & $20 \%$ & $100 \%$ & - & $\begin{array}{c}100 \\
\%\end{array}$ & - \\
\hline 3 & \begin{tabular}{lr} 
Anak & \multicolumn{2}{c}{ mampu } \\
menyebutkan & suku kata \\
dengan baik. & \\
\end{tabular} & $\begin{array}{l}16 \\
\%\end{array}$ & $84 \%$ & $32 \%$ & $68 \%$ & $80 \%$ & $20 \%$ & $\begin{array}{c}100 \\
\%\end{array}$ & - \\
\hline 4 & $\begin{array}{l}\text { Anak mampu membaca } \\
\text { kata dengan baik dan } \\
\text { benar. }\end{array}$ & $\begin{array}{l}12 \\
\%\end{array}$ & $88 \%$ & $12 \%$ & $88 \%$ & $32 \%$ & $68 \%$ & $\begin{array}{l}80 \\
\%\end{array}$ & $\begin{array}{l}20 \\
\%\end{array}$ \\
\hline & Jumlah rata-rata & $\begin{array}{l}33 \\
\%\end{array}$ & $67 \%$ & $56 \%$ & $44 \%$ & $78 \%$ & $22 \%$ & $\begin{array}{l}95 \\
\%\end{array}$ & $5 \%$ \\
\hline
\end{tabular}


Jurnal Golden Age

Vol. 3 No. 01, Juni 2019, Hal. 50-56

E-ISSN : 2549-7367

san

Pra Tindakan

Berdasarkan data tersebut dapat disimpulkan bahwa sebelum tindakan, kemampuan anak dalam mengenal kata kurang dari 40\% dimana ini berarti kemampuan anak masih tergolong sangat tidak baik. Hal tersebut disebabkan karena guru belum menerapkan metode pembelajaran yang tepat dalam pengenalan kata yaitu dengan penerapan metode Cantol Rudhoh. Untuk mengetahui meningkatnya kemampuan anak dalam mengenal kata melalui penerapan metode Cantol Rudhoh di kelas B TK Mahkota Selong, maka peneliti melakukan tindakan Siklus I, Siklus II dan Siklus III dengan penerapan metode Cantol Rudhoh.

\section{Siklus I}

Kemampuan mengenal kata pada anak kelas B TK Mahkota di peroleh angka $56 \%$ untuk alternatif jawaban "Ya" yang berarti masih rendah. Hal ini terlihat karena anak masih kesulitan dalam menyebutkan suku kata dengan baik, belum dapat menyebutkan kata-kata dengan suku kata yang sama, masih kesulitan dalam membaca gambar yang memiliki kata sederhana, dalam membaca kata yang sama masih sering salah, serta kesulitan dalam merangkai suku kata menjadi kata. Hal ini disebabkan oleh masih kurangnya motivasi anak dalam mengikuti pembelajaran sehingga banyak anak yang tidak memperhatikan pembelajaran yang disampaikan oleh guru.Oleh karena itu untuk mengetahui peningkatan kemampuan anak dalam pengenalan kata menggunakan media kartu gambar dengan metode cantol Roudhoh di kelas B TK Mahkota Selong, maka peneliti melakukan perbaikan pada siklus selanjutnya.

Siklus II

Hasil penelitian yang diperoleh selama pembelajaran pada siklus II, kemampuan mengenal kata pada anak kelas B TK Mahkota di peroleh angka 78\% untuk alternatif jawaban "Ya" yang berarti mulai ada peningkatan yang signifikan yaitu banyak anak yang sudah mengenal huruf, banyak anak yang mampu mengenal suku kata dengan baikdan menyebutkan suku kata dengan baik. Pada pertemuan ini ternyata dapat dilihat antusias anak dalam mengikuti pembelajaran. Hal ini juga berarti menunjukkan adanya peningkatan kemampuan dalam mengenal kata pada anakwalaupun belum sempurna. Namun demikian peneliti tetap berusaha untuk lebih meningkatkan kemampuan anak dalam mengenal kata menggunakan media kartu gambar dengan menerapkan metode Cantol Roudhoh dalam pembelajaran. Dengan cara peneliti memberikan tugas kepada anak untuk membaca kata dengan kartu kata. Kemudian peneliti memberikan motivasi kepada anak agar anak tertarik mengikuti permainan membaca dengan kartu kata. Oleh karena itu untuk mendapatkan hasil yang lebih sempurna, peneliti melanjutkan tindakan pada siklus III. 


\section{Siklus III}

Sementara itu, hasil penelitian yang diperoleh selama pembelajaran pada siklus III, kemampuan mengenal kata pada anak kelas B TK Mahkota di peroleh angka 95\% untuk alternatif jawaban "Ya" yang berarti ada peningkatan yang signifikanyaitu banyak anak yang sudah mengenal huruf, banyak anak yang mampu mengenal suku kata dengan baik dan menyebutkan suku kata dengan baik, serta sudah banyak anak yang mampu membaca kata-kata yang dirangkai menjadi kalimat sederhana dengan baik.

Hasil observasi pelaksanaan pembelajaran mengenal kata yaitu peneliti memberikan tugas kepada anak untuk membaca kata dengan kartu kata. Kemudian peneliti memberikan motivasi kepada anak agar anak tertarik mengikuti permainan membaca dengan kartu kata. Persentase pembelajaran pada siklus III ini sudah mengalami peningkatan mencapai 95\%, karena indikator keberhasilan dan nilai ketuntasan yang telah ditetapkan tercapai sehingga penelitian terhenti sampai siklus III. Hasil penelitian menjelaskan adanya peningkatan dengan hipotesis berbunyi "Pembelajaran Melalui Permainan Kartu Gambar Dengan Metode Cantol Roudhoh Dapat Meningkatkan Kemampuan Anak Dalam Pengenalan Kata Di Kelompok B TK Mahkota Selong Tahun Ajaran 2017/2018”.

\section{SIMPULAN DAN SARAN}

Simpulan

Adanya peningkatan kemampuan pengenalan kata pada anak kelas B TK Mahkota Selong melalui metode Cantol Roudhoh ini terbukti dari hasil peningkatan prosentase kemampuan anak dari sebelum tindakan hingga diberikan tindakan sampai siklus III yakni sebelum tindakan sebesar 33\%, peningkatan kemampuan pengenalan kata siklus I mencapai 56\%, siklus II mengalami peningkatan lagi mencapai 78\% dan siklus III mengalami peningkatan sebesar 95\%. Dari hasil diatas juga dapat diperoleh bahwa motivasi anak dalam mengikuti pembelajaran pengenalan kata menggunakan metode Cantol Roudhoh mengalami peningkatan, selain itu anakanak juga lebih semangat dan antusias dalam mengikuti pembelajaran.

a. Saran

\section{Bagi Kepala Sekolah}

Kepala Sekolah dapat menggunakan penelitian ini sebagai referensi atau masukan bahwa metode pembelajaran dengan menggunakan metode Cantol Roudhoh dapat meningkatkan kemampuan pengenalan kata kepada anak.

2. Bagi Guru

Guru hendaknya dapat menggunakan metode pembelajaran yang bervariasi, agar kegiatan belajar mengajar dapat mencapai tujuan belajar mengajar yang telah ditetapkanol dan metode cantol roudhoh adalah metode yang tepat digunakan dalam pembelajaran mengenal huruf dan kata . 
Jurnal Golden Age

Vol. 3 No. 01, Juni 2019, Hal. 50-56

E-ISSN : 2549-7367

3. Bagi Orang Tua

Orang tua dapat melakukan belajar dengan menggunakan metode yang menyenangkan untuk anak sehingga pembelajaran yang ada di sekolah berjalan searah dengan pembelajaran yang ada di rumah.

\section{DAFTAR PUSTAKA}

Agustina, Y., \& Hafidz, I. P. (2017). Optimalisasi Media Permainan Kartu Abaca Untuk Meningkatkan Kemampuan Membaca Dini Pada Kelompok B TK Al-Hasaniyah NW Jenggik. Jurnal Golden Age, 1(02).

Arikunto, Suharsin. (2008). Penelitian Tindakan Kelas. Jakarta : Bumi Aksara.

Asmani, Jamal Ma'mur. (2015). Panduan Praktis Guru PAUD (Melejitkan Kecerdasan Anak). Yogyakarta: DIVA Press.

Iroh, Siti Zahroh, dkk. (2002). Komunikasi Dalam Pengasuhan. Jakarta: Kementrian Pendidikan dan Kebudayaan Republik Indonesia.

Fransiska, F. (2018). MENINGKATKAN KEMAMPUAN KOSAKATA BAHASA DAYAK DESA MELALUI MEDIA FLASHCARD PADA ANAK USIA DINI. Jurnal Golden Age, 2(2), 86-95.

Musbikin, Imam. (2010). Buku Pintar PAUD (Tuntunan Praktis Guru PAUD). Jogjakarta: Laksana.

Nazariah, N. (2017). PENGGUNAAN MEDIA KARTU ABACA FLASHCARDS DALAM PEMBELAJARAN PENGENALAN HURUF ABJAD UNTUK ANAK USIA DINI. Bunayya: Jurnal Pendidikan Anak, 1(2), 50-66.

Kunandar. (2010). Langkah Mudah Penelitian Tindakan Kelas Sebagai Pengambangan Prifesi Guru.Jakarta: PT. Raja Grafindo Persada.

Sanjaya, Wina. (2009). Penelitian Tindakan Kelas.Jakarta : Kencana Prenada Media Group. 